\title{
A Survey of Demotic Astrological Texts
}

\section{Micah Ross}

\begin{abstract}
This survey updates Otto Neugebauer's 1943 list of extant Demotic astrological texts. A brief discussion of each text highlights the contents of the Demotic texts, contextualizes their contents and offers possible re-interpretations. Most dramatically, Text B of Papyrus Vindob. 6286 is brought closer to the Babylonian tradition. In general, these texts bridge the Babylonian and Greek traditions. Evidence for this connection comes from the omen literature, planetary epithets and pseudepigraphy of Babylon, Greece and Egypt. Horoscopes appear separately and their discussion focuses on Demotic terms for the doctrine of lots.
\end{abstract}

\section{Introduction}

In 1943, Otto Neugebauer collected all known Demotic texts on astral science. ${ }^{1}$ In 1996, Brian Bohleke attempted another survey, but he focused on what he believed to be the indigenous Egyptian contributions to astrology. ${ }^{2}$ Because new texts have been discovered and published since the initial list and other texts have been reinterpreted, modern researchers might profit from a recapitulation of the Demotic sources and an assessment of their relationship to the wider astrological tradition. With this goal in mind, Neugebauer's seminal list will be brought up to date, then its elements examined to ascertain their relationship to both Mesopotamian and Greek astrological traditions.

\footnotetext{
${ }^{1}$ Otto Neugebauer, 'Demotic Horoscopes', Journal of the American Oriental Society (1943) [hereafter, Neugebauer, 'Demotic Horoscopes'], vol. 63, no. 2, pp. 115-27, esp. p. 124.

2 Brian Bohleke, 'In Terms of Fate: A Survey of Indigenous Egyptian Contribution to Ancient Astrology in Light of Papyrus CtYBR inv. 1132(B)', Studien zur altägyptischen Kultur (1996), vol. 23, pp. 1-35 and pl. 1.
}

Micah Ross, 'A Survey of Demotic Astrological Texts', Culture And Cosmos, Vol. 11 no 1 and 2, Spring/Summer and Autumn/Winter 2007 pp. 1-25. www.CultureAndCosmos.com 


\section{Survey of the Literature}

\section{Before Neugebauer's List}

Perhaps because his interests were palaeographical, Neugebauer omitted artistic representations from his list. In particular, Neugebauer neglected two horoscopic tomb ceilings at Athribis. Although they contain no Demotic writing, these depictions, published by William Flinders Petrie in 1908, should be added to a list of astrological texts of Roman Egypt. ${ }^{3}$ These two texts start our list of sources:

\section{(1-2) Ceilings of Athribis}

\section{Neugebauer's List}

In order to establish a palaeography of terms used in Demotic horoscopes, Neugebauer compiled a list that he declared to be a comprehensive summation of texts about Egyptian astral sciences. Neugebauer's list contained fourteen items, eight of which were discussed in detail. In Egyptian Astronomical Texts, Neugebauer and Richard Parker excluded astrological material. If the inverse procedure were effected and the astronomical and cosmological texts stricken from Neugebauer's original list, ten items presented in 1943 may be described as astrological and added to our list:

(3-7) A series of 5 horoscopes from Medînet Habû

(8) Ostracon Strasbourg D 521

(9) P. Cairo 31222

(10) A horoscopic coffin lid, now lost, once in the private Maunier collection

(11) P. Berlin $8345^{4}$

(12) P. Cairo 50143

${ }^{3}$ W. M. Flinders Petrie, Athribis. British School of Archaeology in Egypt 14 (London, 1908).

${ }^{4}$ George R. Hughes, 'An Astrologer's Handbook in Demotic Egyptian', in Egyptological Studies in Honor of Richard A. Parker. Presented on the occasion of his 78th Birthday, December 10, 1983, edited by Leonard Lesko (Hanover, New Hampshire, 1986) [hereafter Hughes, Handbook], pp. 53-69. 


\section{After Neugebauer's List}

In 1959, Richard Parker presented P. Vindob. D. 6286, an astrological text in the Vienna collections. ${ }^{5}$ This text may have been overlooked by Neugebauer because it does not include zodiacal signs or planetary names.

(13) P. Vindob. D. 6286

Later, in 1968, Neugebauer and Parker presented two more ostraca containing horoscopes. ${ }^{6}$ The format of these horoscopes differed from their earlier horoscopes.

(14) Ashmolean D.O. 622

(15) O. Berlin P. 6152

In 1983, Eva Reymond attempted to categorize the Demotic papyri in the Vienna collections. She identified four more astrological fragments. ${ }^{7}$ To date, none of these small and fragmentary papyri have been published.

(16) P. Vindob. D. 6639+9906

(17) P. Vindob. D. 6925

(18) P. Vindob. D. $10.013+4877$

(19) P. Vindob. D. 6761

Also in 1983, Richard Parker presented two ostraca with horoscopic texts from Medînet Mâdi. ${ }^{8}$

\footnotetext{
${ }^{5}$ Richard A. Parker, A Vienna Demotic Papyrus on Eclipse- and Lunar-Omina. Brown Egyptological Studies 2 (Providence, 1959) [hereafter Parker, Vienna].

${ }^{6}$ O. Neugebauer and R. A. Parker, 'Two Demotic Horoscopes', Journal of Egyptian Archaeology (1968), vol. 54, pp. 231-35.

${ }^{7}$ Eva A. E. Reymond, 'Demotic Literary Works of Graeco-Roman Date in the Rainer Collection of Papyri in Vienna', in Festschrift zum 100-jährigen Bestehen der Papyrussammlung der Österreichischen Nationalbibliothek. Papyrus Erzherzog Rainer (P. Rainer Cent.) (Wien, 1983) [hereafter Reymond, Rainer], pp. $42-60$.

${ }^{8}$ Richard A. Parker, 'A Horoscopic Text in Triplicate', in Grammata Demotika. Festschrift für Erich Lüddeckens zum 15. Juni 1983, eds Heinz Thissen and Karl-Theodor Zauzich. (Würzburg, 1984), pp. 141-43, pl. 23.
}

Culture and Cosmos 
4 A Survey of Demotic Astrological Texts

(20) OMM 1060

(21) OMM 1154

In 1986, George Hughes and Mark Smith reclassified another papyrus from the Vienna collection, P. Vindob. 6614, which Reymond had published as a 'hermetic' text. ${ }^{9}$

(22) P. Vindob. 6614

In 1992, Michel Chauveau joined P. Carlsberg $66+$ P. Lille and published a description, ${ }^{10}$ but the contents of this papyrus have not been published.

(23) P. Carlsberg $66+$ P. Lille

In 1993, Leo Depuydt identified CtYBR 1132(B) as a table of terms. ${ }^{11}$

\section{(24) CtYBR 1132(B)}

In 1994, Carol Andrews described P. BM 10661 as containing 'references to astronomical events on which the predictions are based... the sun $\left(p^{3} r^{c}\right)$, the moon $\left(i^{c} h\right)$ and the planet Mercury $(s w g)$ are all mentioned. ${ }^{12}$ This papyrus seems to contain predictions relating to foreign countries and politics. The papyrus has not yet been published and too little information is included in the description to determine the astrological techniques.

9 Hughes, Handbook, Addendum, p. 69. Reymond's original publication was From Ancient Egyptian Hermetic Writings. From the Contents of the Libraries of the Suchos Temples in the Fayum, Part II (Vienna, 1977) [hereafter Reymond, Hermetic], pp.143-57.

${ }^{10}$ Michel Chauveau, 'Un traité d'astrologie en écriture démotique', Cahier de récherches de l'Institut de papyrologie et égyptologie de Lille (1992) [hereafter Chauveau, 'Traité'], vol. 14, pp. 101-105.

${ }^{11}$ Leo Depuydt, ‘A Demotic Table of Terms', Enchoria (1994), vol. 21, pp. 1-9.

${ }^{12}$ Carol A. R. Andrews, 'Unpublished Demotic Papyri in the British Museum', Egitto e Vicino Oriente (1994) [hereafter, Andrews, 'Papyri'], vol. 17, pp. 29-37, esp. p. 31.

Culture and Cosmos 
In 2005, George Hughes posthumously presented another horoscope, ostracon 12786 1774, in the Brooklyn Museum. ${ }^{13}$

(26) Brooklyn Museum 127861774

Ideally, these papyri could be set in chronological order and developments in Egyptian astrology could be clearly traced. However, many of the papyri cannot be assigned a precise date. Furthermore, some of them appear to have been copies of older texts. Hence, only a roughly chronological presentation can be attempted. In other words, P. Vindob. D. 6286 and Ostracon Strasbourg D 521 represent an era before the standardization of zodiacal signs. P. Carlsberg $66+$ P. Lille, P. Cairo 31222, P. Cairo 50143, and P. Berlin 8345 all contain zodiacal signs. P. Vindob. D. 6614 and CtYBR 1132(B) present the topoi and terms, elements known from Greek astrology which postdate the standardization of zodiacal signs.

Also, as Mark Depauw rightly observes, horoscopes may be considered documentary texts as well as astrological texts. ${ }^{14}$ Thus, in this article, horoscopes will be presented after the other texts have been discussed. In this way, the connection with the Demotic material and both its precursors and legacies may be traced.

\section{Astrological Sources}

\section{P. Vindob. D. 6286 (Text 13)}

P. Vindob. D. 6286, published by Richard Parker (see note 5: Parker, Vienna), preserves the best-known astrological text written in Demotic. According to Parker, the late second or early third century CE copy preserved omens from two earlier compositions. Parker noted that neither of these compositions contained references to zodiacal signs, which seem

${ }^{13}$ George R. Hughes, Catalog of Demotic Texts in the Brooklyn Museum. Oriental Institute Communications 29 (Chicago, 2005), p. 55.

${ }^{14}$ Mark Depauw, A Companion to Demotic Studies. Papyrologica Bruxellensia 28 (Brussels, 1997), p. 107. 
to have originated in the astronomical diaries of the fifth century BCE. ${ }^{15}$ Furthermore, the omens in both compositions conform to the Mesopotamian tradition of astrology which predicts general events such as floods and revolts, not the personal affairs of an individual.

Parker called the first of the two compositions Text A. From a concordance of Mesopotamian and Egyptian calendars, he established its date between $625 \mathrm{BCE}$ and $482 \mathrm{BCE}$. Parker argued that Text A had Mesopotamian antecedents and Greek descendants, a claim strengthened and articulated by Clemency Williams. ${ }^{16}$

Whereas comprehension of the incomplete Text A may be improved by future discoveries, considerable corrections may be offered now for Text B, the second of the two compositions. In the manuscript of Text B, the upper half presents omens drawn from the appearance of the Sun, and the lower half discusses omens drawn from the appearance of the Moon. Such an arrangement had been dismissed by Parker:

The essential figure of every vignette is a disk, and an important problem is posed by the fact that in all the upper halves of the columns, it is referred to as $p 3 \mathrm{itm}$, while in all the lower ones it is named ich.... Moreover, in all vignettes a full disk is shown, never a crescent or incomplete moon. This would seem to eliminate the distinction such as full moon for $p 3 \mathrm{itm}$ and $i c h$ for all the other phases. Nor does it seem at all possible to consider p3 itm as referring to the sun disk. It is certainly true that such is the original meaning of $2 h^{\circ} \circ$, of which itm is a demotic variant, but in the later period the moon as well can be so denoted; and how, we may ask, could the sun figure in situations with stars, black disks, etc.? With the naked eye it is physically impossible to see anything in or near the sun in a clear sky. We are driven then to accept both $p^{3} \mathrm{itm}$ and $i c h$ as referring to the moon and

\footnotetext{
${ }^{15}$ For discussion, see Francesca Rochberg, The Heavenly Writing (Cambridge, 2004) [hereafter Rochberg, Writing], pp. 130-31.

${ }^{16}$ Clemency Williams, 'Some Details on the Transmission of Astral Omens', in From the Banks of the Euphrates, ed. Micah Ross (Winona Lake, IN, 2007).
} 
moreover to the moon when it is full or, we may suppose, very near to being full. ${ }^{17}$

Parker asks how the sun could figure in situations with stars and black disks. If the questions of optics and celestial mechanics are abandoned momentarily for the simple question of precedent, a sensible solution emerges. Thus, instead of 'how', let us ask only 'Did the sun figure in situations with stars, black disks, etc.'? In this case, the answer is affirmative.

In Mesopotamian omens, the appearance of the sun accompanied by stars, disks, halos and other improbable events frequently served as the protases of omens. In the nearly half-century since Parker first published P. Vindob. D. 6286, the Šamaš section of Mesopotamian omen series entitled Enuma Anu Enlil (hereafter, EAE) has been reconstructed. These omens once filled Tablets 23 through 29 of the series of seventy cuneiform tablets. ${ }^{18}$ Among their protases, these omens contain nearly every condition recorded in the upper half of Text $\mathrm{B}$, show that the sun did figure in the situations eschewed by Parker, establishes that itm could refer to the sun, and confirms a Mesopotamian precedent.

Because the tablets of EAE are as broken as P. Vindob. D. 6286 is worm-eaten, no direct quotations may be found, but enough survives to establish beyond doubt that similar omens were considered in both Mesopotamian and Egyptian solar omens. This lack of direct corroboration does not destroy our hypothesis because multiple versions of the omen series existed, some of which have undoubtedly not yet been published. Just as the apodoses were altered to fit better with the Egyptian political situation, ${ }^{19}$ protases were also changed. In spite of such changes, the Demotic descriptions of the sun fit well with Mesopotamian observations. Specifically, Text B of P. Vindob. D. 6286 preserves thirteen written descriptions of the sun's appearance. These protases from the columns, fragments and vignettes demonstrate clearly their connection with Mesopotamia.

\footnotetext{
${ }^{17}$ Parker, Vienna, p. 35.

${ }^{18}$ Wilfred H. van Soldt, Solar Omens of Enuma Anu Enlil: Tablets 23(24)-29(30) (Leiden, 1995).

${ }^{19}$ See Parker, Vienna, pp. 6-7.
} 


\section{A Survey of Demotic Astrological Texts}

No protases are preserved for Columns I through VI. Indeed, even in Column VII, the protasis is broken. '[If you see the disk. . .] rising [southwards. . .] there being one star outside it'. Likewise, in Column X, the protasis is badly broken, but a condition with 'one star' is preserved. The first phrase of Column VII is somewhat ambiguous, but the second phrase, 'while there is one star outside it', echoes the appearance of a single star with the sun. Among the Mesopotamian omens, one reads: 'If a disk rises at an unexpected time, and a bright star is present in its radiance. . . ${ }^{20}$ while its variant ${ }^{21}$ substitutes sun for disk. Another omen ${ }^{22}$ begins, 'If a star is present when a disk rises'. Likewise, an omen ${ }^{23}$ considers the condition 'If a disk rises during the middle watch of the night and a star stands in front of it'. And, another ${ }^{24}$ reads, 'If a star stands in front of the sun'. Notwithstanding the fact that the commonplace word sun has generally been replaced with the less common word disk, the sun's appearance with a single star is a rather pedestrian omen, albeit one discounted by both Parker and optical plausibility.

In Column VIII, the protasis is again broken. It reads: '[If you see the disk colored complete]ly on the 15th (lunar) day, there being a black [disk] around it'. The first two words may describe the sun as 'coloured completely'. This exact phrase does not occur in EAE, but the colour of the sun is discussed frequently in EAE. One large section ${ }^{25}$ considers the appearance of the sun on specific days of the lunar month generally, and other sections consider the appearance of the sun on the days of specific lunar months. Particularly, the phrase 'on the 15th lunar day' corresponds with two passages. ${ }^{26}$ The condition 'there being a black [disk] around it' is discussed by Parker. "The doubt that we have itm "disk" here, despite the bottom stroke of $i$ and the certain $m$ and the disk determinative results

\footnotetext{
${ }^{20}$ EAE 24.2.e.

${ }^{21}$ EAE 24.4.8a.

${ }^{22}$ EAE 24.3.15.

${ }^{23}$ EAE 24.3.23.

${ }^{24}$ EAE 26.4.24.

${ }^{25}$ EAE 25.3.22-68a.

${ }^{26}$ EAE 24.3.40-45 and 24.Cb.9.
} 
from the final determinative of the brazier rather than the god, as everywhere else. ${ }^{27}$ In fact, this confusion may be clarified by the Mesopotamian omens. According to the Demotic text, the sun is 'inside' the black object. In EAE, the sun is frequently 'inside' black objects: clouds, ${ }^{28}$ webs ${ }^{29}$ and halos. ${ }^{30}$ One particular omen ${ }^{31}$ considers the sun inside a black 'radiance'. Both the halo and the radiance provide a diskshaped area which could contain the sun, but no Coptic examples can decide the question. Perhaps the translation of this term proved difficult for the scribe, so he attempted to distinguish between the uses of itm by changing the determinative. Even so, this omen in the Demotic papyrus was probably derived from a Mesopotamian source.

In Column IX, the protasis is complete. It reads: 'If you see the disk colored completely, its "scent" red downward in it, there being one black disk on its right another black disk on its left'. The same 'left / right' division occurs in Fragment 2a, in which the entire protasis is destroyed except for mention of something 'on its left' and 'on its right'. Parker questions the translation of scent and suggests a scribal error for rays. Such a reading could correspond with an omen ${ }^{32}$ which discusses the results of the sun's radiance being red at the rising. If this reading is accepted, the black disk in Column VIII should probably be associated with a halo, not the radiance. In EAE, appearances on the right and left are often coordinated, ${ }^{33}$ but one particular protasis ${ }^{34}$ which reads 'If a normal disk is present and one disk stands to the right (and) one to the left' seems closely related to the protasis in Column IX. Column $\mathrm{X}$ is hopelessly broken and Column XI is missing altogether.

\footnotetext{
${ }^{27}$ Parker, Vienna, p. 39.

${ }^{28}$ EAE 23.4a.4, 23.5.7-8, 23.5.10-12, 23.8.3, 29.1a.6, 29.3.22-23, 29.3.57, 29.3.61, 29.3.95.

${ }^{29}$ EAE 28.75 .

${ }^{30}$ EAE 27.2.5.

${ }^{31}$ EAE 25.3.4.

${ }^{32}$ EAE 25.3.2.

${ }^{33}$ EAE 24.2.a; 24.Ca.8'; 24.Cb8; 25.3.10.

${ }^{34}$ EAE 24.3.30.
}

Culture and Cosmos 
In Column XII, the text is largely complete. The protasis reads: 'If you see the disk, [colored,] there being three stars inside it'. The observation of stars is a common occurrence, but this protasis corresponds closely to an omen ${ }^{35}$ which reads, 'If the stars stand within the disk'. Another omen ${ }^{36}$ considers the possibility of three stars. It reads: 'If a disk rises on the horizon, variant: at noon, and two, variant: three stars are present'. In a commentary text ${ }^{37}$ the phrase 'If the stars stand within a disk' is explained by the gloss 'planets are present during an eclipse'. Clearly, Parker's concerns about the visibility of such phenomena were shared by the Mesopotamian diviners.

In Column XIII, the protasis is complete: 'If you see the disk rising and lighting up the sail(s), on a day'. Here, Parker declines to translate $\check{s y s ̌, ~ w h i c h ~ c a r r i e s ~ a ~ h o u s e ~ d e t e r m i n a t i v e . ~ H e ~ p r e s e n t s ~ t h e ~ h y p o t h e s i s ~ t h a t ~}$ the "word has something to do with the time when the moon is full. ${ }^{38}$ This hypothesis finds support in Coptic, in which the moon is described as Moye $\mathbf{e q w} \boldsymbol{w} w$, 'having grown full'. ${ }^{39}$ Parker notes that sh.t 'lighting up' differs from the standard orthography and carries the brazier determinative. This determinative fits the gamut of meanings which includes kindling and starting fires. Perhaps the ancient scribe intended the word which Parker read as h.t and translated as 'sails' to be interpreted as $h w i$, 'rain(cloud)'. Should this have been the case, parallels exist with EAE, in which an entire tablet ${ }^{40}$ considers the appearance of the sun in cloudbanks.

In Column XIV, the protasis is complete. It reads: 'If you see the disk rising in the east at the beginning of the year, its southern area covered'. The word covered is the only word preserved in the protasis of Column XVII. Protases for omens on the first day of the year are also considered

\footnotetext{
${ }^{35}$ EAE 24.3.13.

${ }^{36}$ EAE 24.3.14.

${ }^{37}$ EAE 24.Cc.2.

${ }^{38}$ Parker, Vienna, p. 44.

${ }^{39}$ Walter E. Crum, A Coptic Dictionary (Oxford, 1929) [hereafter Crum, Coptic], p. 606.

${ }^{40}$ EAE 29.
} 
in EAE. First, they occur as the first day of the lunar month. ${ }^{41}$ Some omens ${ }^{42}$ have an ambiguous placement of the phrase 'at the beginning of the year', which may apply to the protasis as well as the apodosis. EAE considers the possibility that the sun is 'covered (by clouds)', ${ }^{43}$ but this observation is not paired with some portion of the sun. Perhaps, the 'southern area' of the $\mathrm{sky}^{44}$ was intended.

In Column XV, the protasis is too broken to consider, but Column XVI reads: 'If you see the disk divided at one place'. Here the limits of plausible observation of either the sun or the moon are strained. While no extant Mesopotamian omen begins this way, a commentary text ${ }^{45}$ contains a related passage. For texts with the Sumerian logogram BAR, the Akkadian word zazûu 'to divide into halves' or mešlu 'half' should be read. Apparently, this reading strained the credulity of Mesopotamian observers as well - the whole phrase is explained with the gloss 'If the sun is half dark when it sets'.

Thus, all the columns of text, with the possible exception of Column XIII may be associated with Mesopotamian precedents. Two fragments contain texts from the protases. In Fragment 1a, the entire protasis remains: 'If you see the disk, colored entirely, there not being any other color in it'. In Fragment 1b, only the word red remains. These protases cannot be reliably related to any Mesopotamian omen. True, Mesopotamian omens often considered colours of the sun, but they also referred to coloured spots and sprinkles of blood. Red was one of the four Mesopotamian colours and occurs frequently throughout EAE. In fact, the Demotic text contains only two colours of disk - red and black. Both are Mesopotamian colours.

As for the vignettes, they contain a wider array of colours, but these pictures represent a technique not available to the Mesopotamian scribes who wrote on clay. Clearly, the Demotic papyrus was not a direct translation, but a reworking of Mesopotamian ideas in an Egyptian context. Nine images of the sun occur in the vignettes. Some vignettes can be correlated with the text even though an error has occurred in the

\footnotetext{
${ }^{41}$ EAE 23.1.1-3, 23.2.1-2; 24.3.45.

${ }^{42}$ EAE 29.3.28-29; 29.3.57.

${ }^{43}$ EAE 26.1.34-37.

${ }^{44}$ EAE 24.1.12; 24.3.14, 24.3.27; 29.3.91-95.

${ }^{45}$ EAE 27.Ca.4.
} 
order. The vignettes of Column XII (a black disk with a light blue center), Column XVI (a disk with a yellow right half and a light blue left half), Fragment 1 (a disk with a light brown right half and a yellow left half), Fragment $2 \mathrm{a}$ (a light brown disk) and Fragment $2 \mathrm{~b}$ (another light brown disk) do not represent preserved text. It is possible that the colours have shifted somewhat since the original painting, but aside from blue and light brown, these pictorial representations roughly agree with the Mesopotamian descriptions of the sun.

With this re-examination, Parker's interpretation of P. Vindob. D. 6286 changes in two ways. First, the upper and lower registers represent solar and lunar omens respectively. Secondly, the Demotic text corresponds to a Mesopotamian precedent. Parker suspected a Mesopotamian origin for Text B, but he did not present speculation as certainty:

The reader will have observed that while I confidently gave Text A a Babylonian origin in the title to Chapter III, I have not so committed myself in the title to the present Chapter. The reason is simple. There is no such clear and unmistakable evidence of a Mesopotamian origin for anything in Text B. Nevertheless there are indications that point in that direction. ${ }^{46}$

He continues, almost presciently:

Once the complete text of Enuma Anu Enlil is published it may well be that we shall have exact parallels between it and Text B. That would obviously settle the problem definitely. But until Enuma Anu Enlil is completely available we must make do with what we have and that leads to conjecture rather than fact. ${ }^{47}$

Although Parker suspected a Mesopotamian precedent, the details of the Mesopotamian text could not be guessed. The parallel arrangement of solar omens and lunar omens in the upper and lower sections of Text B conforms to a division of the text contrary to Parker's interpretation. The decision to separate the two sections rests on the authority of the

\footnotetext{
${ }^{46}$ Parker, Vienna, p. 53.

${ }^{47}$ Parker, Vienna, p. 54.
} 
Mesopotamian precedent and also on a conformity with the standard usage of the Demotic noun itm. The claim of a Mesopotamian origin is confirmed only by an admittedly patchy correspondence of these two indirectly related and fragmentary texts.

Even though the correspondence may be limited, EAE clarifies some readings in P. Vienna D. 6286. Some of these have already been seen among the protases, but a Mesopotamian origin would explain why the Egyptian royal title $p r$ - 3 , 'Pharaoh', has generally been replaced with the more general $n s w$, 'king'. ${ }^{48}$ In the Demotic papyrus, this 'king of Egypt' slaughters his ir- $c h 3 w$. Parker translated this word almost tautologically as 'adversary.' In the surviving text of EAE, the prediction is more dire: the king slaughters only his subjects. ${ }^{49}$ Both texts contain predictions which will occur 'in three years' ${ }^{50}$ Finally, the Demotic phrase 'the King of Egypt will accomplish his lifetime, ${ }^{51}$ may parallel the Mesopotamian prediction 'the king of the world's reign will be long-lasting' ${ }^{52}$ While the details gleaned from EAE - the publication of which took nearly a century - have invalidated some of Parker's assumptions, they have also confirmed his suspicions: Text $\mathrm{B}$ was an Egyptian recension of Mesopotamian astrology.

\section{Ostracon Strasbourg D 521 (Text 8)}

The next oldest astrological material preserved in a Demotic source is Ostracon Strasbourg D 521. Published alongside horoscopic material, ${ }^{53}$ this ostracon contains a list of five planets, then a list of twelve zodiacal signs paired with the twelve months of the Egyptian calendar. Drawing a correspondence between these signs and the months, Neugebauer arrives at a date for the creation of the list. He places it between $250 \mathrm{BCE}$ and $126 \mathrm{BCE}$, although the ostracon itself might be more recent. This date corresponds roughly with the now-destroyed zodiac at Esna, the oldest

\footnotetext{
${ }^{48}$ Andrews, Papyri, p. 30 notes the same circumlocution in P. BM 10660.

${ }^{49}$ EAE 24.3.7; 24.3.9; 25.1.22; 26.1.32.

${ }^{50}$ In Demotic, this apodosis is in Column XIII of P. Vindob. 6286. In Akkadian, it is in EAE 25.1.5.

${ }^{51}$ Frag. 1, Col. A.

${ }^{52}$ EAE 29.3.9.

${ }^{53}$ Neugebauer, 'Demotic Horoscopes’, pp. 121-22.
}

Culture and Cosmos 
Egyptian monumental representation of the zodiac. As noted before, the zodiacal signs have a Mesopotamian precedent, but so do the names in the 'list of living stars' on Ostracon Strasbourg D 521.

As Neugebauer notes, the text preserves the 'younger' Mesopotamian planetary order. The planet and the associated deity may be considered in order. Saturn (called Horus the Bull) is identified with Re, the solar divinity. Astronomically, this pairing is difficult to explain. Presumably, the sun ought to be identified with Re. However, twice in the Mesopotamian text MUL.APIN, ${ }^{54}$ Saturn is explicitly identified as 'the star of the sun'. This reference recurs in Greek, when Diodorus Siculus ${ }^{55}$ and Hyginus ${ }^{56}$ report that Chaldaeans called Saturn 'the sun'. ${ }^{57}$

Next, Mars (called Horus the Red) is identified with 'the fierce lion'. Neugebauer has drawn attention to the Greek legacy of this phrase with A $\mu$ ivors but neglected the fact that in Babylon the planet Mars was associated with Nergal, a god represented by a panther. Although Reiner equates Nergal and Mars, ${ }^{58}$ MUL.APIN seems to identify Nergal with a particular fixed star. ${ }^{59}$ Among the astrological reports, however, Nergal appears among Mars' omens, ${ }^{60}$ and one text ${ }^{61}$ explains the phrase 'If Nergal stands in Scorpius' as 'Mars stands in it'.

54 MUL.APIN 2.1.39 and 2.1.64 in Herman Hunger and David Pingree, MUL.APIN: An Astronomical Compendium in Cuneiform. Archiv für Orientforschung Beiheft 24 (Horn, 1989) [hereafter Hunger and Pingree, MUL.APIN,].

55 2.30.3-4.

${ }^{56}$ De astronomia $2.42 .8-10$.

${ }^{57}$ For a fuller discussion, see Hunger and Pingree, MUL.APIN, p. 147.

58 Erica Reiner, Astral Magic in Babylonia. Transactions of the American Philosophical Society, vol. 85, pt. 4 (Philadelphia, 1995) [hereafter Reiner, Astral Magic ], pp. 6-7.

${ }^{59}$ MUL.APIN 1.1.28.

${ }^{60}$ Hermann Hunger, Astrological Reports to Assyrian Kings. State Archives of Assyria 8 (Helsinki, 1992) [hereafter Hunger, Reports], p. 72, text 114, line 8 and p. 296, text 541, line 12 .

${ }^{61}$ Hunger, Reports, p. 279, text 502. 
Then, Mercury (called $s w g 3$, a name related to 'small') appears next to Thoth, the god of wisdom, scribes and learning. In Mesopotamia, Mercury was linked with Nabu, the Mesopotamian scribal god. This connection persisted into Greek, with Mercury and Hermes.

With Venus, Ostracon Strasbourg D 521 parts ways with the Mesopotamian tradition. In Mesopotamian literature, Venus is indicated by the Dilibat, or Ištar. The Demotic text refers to Venus as 'Horus, the son of Isis'. As the premier female deity, an association of Isis and the planet Venus seems appropriate, but the intervention of Horus is confusing. Perhaps the Demotic scribe continued the general trend of calling the superior planets Horus (in which Saturn is Horus the Bull, Jupiter is Horus the Mystery, and Mars is Horus the Red). No other text associates Venus with Horus.

Finally, Jupiter (called Horus the Mystery) is associated with Amun. This pairing makes linguistic sense in Demotic because 'the mystery' is echoed by the name Amun which means 'hidden'. Of the Mesopotamian planetary names, Jupiter is the least consistent: Jupiter may be called 'heroic', ${ }^{62}$ but the most frequent name SAG.ME.GAR associated with Nibiru is not fully understood. ${ }^{63}$ SUL.PA.E..A defies connection with the Mesopotamian pantheon, but ${ }^{\mathrm{d}}$ AMAR.UTU connects with Marduk. Perhaps Marduk was the root of the association: both Marduk and Amun were syncretistic gods as evidenced by the ancient poems 'The Fifty Names of Marduk' and the 'Hymn to Amun'.

\section{P. Carlsberg $66+$ P. Lille (Text 23)}

P. Carlsberg $66+$ P. Lille (see note 10) contain a list of decans. The decans represent an indigenous Egyptian astronomical tradition dating back to at least the Tenth Dynasty. ${ }^{64}$ Whereas the Mesopotamians divided the sky into twelve portions after the fifth century, the Egyptians had divided the sky into thirty-six sections since about the second millennium. After the advent of Mesopotamian astronomy, the decans were relegated to the realm of astrology, although they may not have originally had any divinatory meaning.

\footnotetext{
${ }^{62}$ Reiner, Astral Magic, p. 4.

${ }^{63}$ Rochberg, Writing, p. 28.

${ }^{64}$ See O. Neugebauer and Richard A. Parker, Egyptian Astronomical Texts. Vol. 1: The Early Decans. Brown Egyptological Studies 3 (Providence, 1960), p. 4.
} 
The influence of Mesopotamia can be discerned in this papyrus, because the decans are presented as subdivisions of the zodiacal signs. The whole composition, however, is introduced by a line which names 'Imhotep the Great, son of Ptah' and also 'Pharaoh Djoser' written as ' $T s r$ ' ${ }^{65}$ Presumably the Demotic scribes assigned the decans to the Third Dynasty. Unfortunately, the text may be too broken to determine if they also ascribed the origin of the zodiacal signs to remote antiquity. Perhaps fragments will be restored and a more certain reading will be advanced in the publication of these papyri.

\section{P. Cairo 31222 (Text 9)}

In 1951, George Hughes presented P. Cairo $31222,{ }^{66}$ a text which contains omens for the Sun, Moon, and five planets being in Sagittarius or Gemini during the heliacal rising of Sothis or, in one case, its heliacal setting. Dated to the Roman period by palaeography, this text uses zodiacal signs but considers only omens with an effect for the entire country. There are no elements of personal astrology. Hughes correctly notes that similar material had been preserved in the first book of Hephaestio of Thebes, but the Mesopotamian precedents were not sufficiently known at the time of the publication of P. Cairo 31222 to draw parallels.

Although the heliacal risings of Sothis have long been considered a particularly Egyptian area of astronomical interest, Mesopotamians also drew omens from the conditions of heliacal risings. In fact, the fiftieth and fifty-first tablets of EAE are dedicated to such omens. ${ }^{67}$ Generally, the Mesopotamians watched for early and late risings of fixed stars; but occasionally other phenomena - such as brightness or darkness of the star and the visibility of planets - are considered. ${ }^{68}$ Though the positions of planets in zodiacal signs are not explicitly preserved, the omens based on the planets in zodiacal signs are preserved in closely related texts. ${ }^{69}$

${ }^{65}$ Chauveau, 'Traité', p. 102.

${ }^{66}$ George R. Hughes, 'A Demotic Astrological Text', Journal of Near Eastern Studies (1951), vol. 10, pp. 256-64.

67 Erica Reiner and David Pingree. Enuma Anu Enlil, Tablets 50-51. In Babylonian Planetary Omens, Part 2 (Malibu, 1981).

${ }^{68}$ EAE 51.12.1-21.

${ }^{69}$ See EAE 50.3.1-36. for examples. 
P. Cairo 31222 preserved the planetary order most common to Greek horoscopes. In this respect, it represents a slight divergence from standard Egyptian practice since the Greek planetary order (Sun, Moon, Saturn, Jupiter, Mars, Venus, Mercury) has not been identified as the organizing principal of any Demotic horoscopes. Thus, P. Cairo 31222 recombines ideas and techniques then present in Mesopotamia and perhaps even Egypt. The closest parallels, however, lie in the Greek legacy.

\section{P. Cairo 50143 (Text 12)}

Wilhelm Spiegelberg published images of P. Cairo 50143 in 1932, and Otto Neugebauer gave a transcription and translation of this fragmentary text. This brief text contains the name of Mercury and may preserve the triplicity of Gemini, Libra and Aquarius, a triplicity ruled at night by Mercury according to the Greco-Roman era astrologers. Although the connection of triplicities with planets may be described as a Greek phenomenon, triplicities are also known from Mesopotamian texts. ${ }^{70}$ Perhaps Egypt played a role in the development of this technique, but more certain evidence must come from a less fragmentary source.

\section{P. Berlin 8345 (Text 11)}

In 1986, George Hughes presented P. Berlin 8345, a difficult piece which listed the influences of Venus and Mercury in each of the twelve topoi. These divisions of the zodiacal signs are unknown among the published Mesopotamian material, but appear frequently in Greek texts.

P. Vindob. D. 6614 (Text 22) with an excursus on Vindob. D. $6639+$ 9906 (Text 16)

In 1977, Eva Reymond presented P. Vindob. D. $6614 .{ }^{71}$ At this time, P. Vindob. D. 6614 was described as an interpretation of the process of creation. ${ }^{72}$ This papyrus was not mentioned when Reymond listed known

70 See Francesca Rochberg-Halton, 'TCL 6 13: Mixed Traditions in Late Babylonian Astrology', Zeitschrift für Assyriologie und vorderasiatische Archäologie (1987), pp. 207-228; and Micah Ross, 'All's DUR That Ends twr', in From the Banks of the Euphrates, ed. Micah Ross (Winona Lake, IN, 2007) [hereafter Ross, 'DUR']. Also F. Rochberg-Halton, 'New Evidence for the History of Astrology', Journal of Near Eastern Studies (1984), vol. 43, no. 2, pp. $115-40$.

${ }^{71}$ E. A. E. Reymond, Hermetic.

${ }^{72}$ E. A. E. Reymond, Rainer, p. 37.

Culture and Cosmos 
Demotic astrological papyri in the Vienna collections. Reymond described the contents of the largest of these fragments, P. Vindob. D. $6639+9906$ : 'It deals with predictions relating to horoscopic houses at the time of $h t p$-setting and the $h^{c}$-rising of an astral body, the name of which is not preserved, when it comes in conjunction with the Moon. ${ }^{73}$

In his edition of P. Berlin 8345, George Hughes provides the results of a collaboration with Mark Smith. They dismiss Reymond's interpretation of P. Vindob. D. 6614 and consider the text as the compilation of the influences of first the sun, then the moon in the tenth house.

\section{CtYBR 1132(B) (Text 24)}

In 1994, Leo Depuydt published a table of terms, or öpı in Greek. Ptolemy records three traditions for these subdivisions of the zodiac. First, Ptolemy describes one system of terms as Egyptian, by which he may have had in mind Nechepso and Petosiris. He describes another system as Chaldaean. Finally, Ptolemy claims to have found a verbose and damaged ancient manuscript which at first he could scarcely understand. ${ }^{74}$ After some effort, this manuscript revealed a third, preferred, system of the terms. None of these versions squares with the Demotic copy presented by Depuydt.

The fact that the terms published by Depuydt agree with none of these traditions is less surprising than Ptolemy's claims about an ancient manuscript. It is possible that the manuscript was nothing more than a convention of literary fiction. Indeed, Abu Ma'shar doubted the story. ${ }^{75}$ On the one hand, worm-eaten papyri and powerful spells hidden under the feet of statues are standard literary tropes in Egyptian pseudepigraphy. In one famous instance, the Memphite theology cites a 'worm-eaten' papyrus as the original text. In the Memphite theology, also called the Shabaka Stone, the papyrus was so damaged that it could not be understood from beginning to end and Shabaka had to rewrite it. Two spells in the Book of the Dead ${ }^{76}$ both claim to be from a papyrus found by

\footnotetext{
${ }^{73}$ Reymond, Rainer, p. 53.

${ }^{74}$ See Deborah Houlding's article in this volume.

${ }^{75}$ Liber introductorii maioris ad scientiam judiciorum astrorum, VII, 6, ed. R. Lemay, (9 vols, Naples, 1995-96), II, p. 325 and V, p. 197.

${ }^{76}$ Chapters $30 \mathrm{~A}$ and 64 , as translated by Raymond Faulkner, available in a modern edition by James Wasserman, ed. The Egyptian Book of the Dead. (San
} 
Hordedef under the feet of a god. ${ }^{77}$ (The attributions are so similar that one wonders which was under the left foot and which was under the right.) The pseudepigraphies are not limited to religious mythologies. The medical text Papyrus Ebers shares in this tradition - one section purports to be from a book found under the feet of a god during the reign of a First Dynasty king - but another section echoes Ptolemy. After remedies ascribed to the gods, the medicinal uses of a plant are attributed to an old papyrus. ${ }^{78}$ Lest these tropes be considered only an Egyptian phenomenon, PGM CXXII, 1-55, a spell invoking Aphrodite, declares itself to be 'an excerpt of enchantments from the holy book called Hermes, found in Heliopolis in the innermost shrine of the temple, written in Egyptian letters and translated into Greek': enchantment using apples. ${ }^{79}$ This attribution is not to be believed: both the goddess and the fruit betray a Greek, not Egyptian, origin.

On the other hand, Ptolemy gives more details than other pseudepigraphies. He gives some information about the whole manuscript: it is long and with many examples. Ptolemy also notes that the manuscript had been marked with dots, a detail not expected from a lie. In fact, several other Greek astronomical manuscripts have been marked with strange, inexplicable dots. Perhaps they do not represent the same tradition, but the dots do present a similar system of notes. Furthermore, Ptolemy describes the end of the manuscript as better preserved than the beginning, a detail which Robbins grudgingly acknowledges to have the ring of truth. ${ }^{80}$

Francisco: Chronicle Books, 1994). Chapters 30A and 64 appear on p. 103 and pp. 106-07, respectively.

${ }^{77}$ That is, the statue of a god.

${ }^{78}$ See B. Ebbell, The Papyrus Ebers (London, 1937), p. 12 for an accessible English summary and translation. The passages are in P. Ebers, col. 103 and col. 47 , respectively.

${ }^{79}$ Hans Dieter Betz, The Greek Magical Papyri in Translation. Vol. 1: Texts. Second edition (Chicago, 1992), pp. 316-17. Here, a footnote indicates that 'the innermost shrine' refers to the temple library. The Egyptian precedent is clearer if this interpretation is dismissed and it is remembered that statues of the gods resided in the innermost shrines.

${ }^{80}$ See F. E. Robbins, ed. and trans., Ptolemy: Tetrabiblos, (Cambridge, Massachusetts, 1948), p. 103, note 1 to the translation. 
20 A Survey of Demotic Astrological Texts

Although Ptolemy gives many details, the story is far from complete. Ptolemy never tells us the language of the original. One suspects Greek because a Demotic text would have prompted a comment. Egyptian texts are rarely full of examples or long in explanation. Also, Ptolemy uses Mesopotamian sources in the Almagest without citing 'a tablet'. Perhaps he read Greek recensions. And, why would he trust as authoritative a text to which he admits his difficulty in puzzling out? In this passage, Ptolemy's language seems to echo Shabaka's introduction. He admits he could hardly figure out what the text was about. While a decayed book might excite the romantic imaginations of poets, Ptolemy is generally more sober in his reasoning. In fact, even though the system of terms is presented on the authority of the aged manuscript, Ptolemy ultimately justifies his preference for this system by its natural and consistent composition.

Aside from Depuydt's instance of Egyptian terms, one other papyrus, P. Carlsberg 89, is currently being studied by Andreas Winkler. This text is preserved in Copenhagen where approximately one-third of the temple library of Tebtunis is stored. Another third of the temple library, including the terms published by Depuydt, resides in New Haven. Also at New Haven is a yet unpublished papyrus (P. CtYBR 422b) which purports to explain lunar aspects by the authority of a newly 'discovered' papyrus. Perhaps either Ptolemy's manuscript or his frame-story may still find a Demotic precursor.

All of these texts were used to understand the astrological meanings of the planetary positions. Some texts such as P. Vindob. D. 6286 provided general interpretations for phenomena such as eclipses. Others such as P. Berlin 8345 contained readings tailored for individuals. Of the thirteen texts containing material for interpretation, only seven have been published.

\section{Horoscopes}

Even though the earliest evidence for personal astrology comes from Mesopotamia, ${ }^{81}$ the practice was well-developed in Egypt. Manuals of interpretation provide the best evidence for astrological techniques, but horoscopes provide information about the dates of astrological enquiry and the proliferation of the practice of personal astrology. The Demotic horoscopes published by Neugebauer and others are generally earlier and less numerous than their Greek counterparts, but later and more

${ }^{81}$ Francesca Rochberg, Babylonian Horoscopes (Philadelphia, 1998). 
numerous than the Mesopotamian examples. One consistency is that they all lack recorded interpretations. No firm conclusions, however, should be drawn about the relative paucity of these horoscopes; nor should they be interpreted as strongly defining a period of astrological activity. More examples will undoubtedly come to light, and a corpus of about forty horoscopes from the Late Roman era (found at Medînet Mâdi) are currently in preparation. A survey of the fourteen horoscopes, nevertheless, clarifies the vocabulary used and delineates the development of the astrological tradition.

\section{The Coffin of Htr from Luxor (Text 10)}

Among the fourteen horoscopes is one depiction of planetary positions on a coffin lid. The Coffin of $H t r$, first published by Brugsch but now lost, contained a circle of zodiacal signs. In the divisions of this zodiac were written the names of the planets and the ascendant. These positions correspond to some time in October $93 \mathrm{CE}$. If these positions indicate the arrangement of the heavens at $H t r$ 's birth, it can be determined that they were recorded about $125 \mathrm{CE}$.

\section{Tombs at Athribis (Texts 1 and 2)}

The usefulness of a horoscope after the death of the individual for whom it was cast challenges modern perceptions of divination, but horoscopes also appear in other Egyptian funerary contexts. Whether or not the two ceilings of Athribis contain an indication of the zodiacal sign which occupied the ascendant, the texts consist of a depiction of the zodiac, with the planets positioned in each sign. The zodiacal circles have a beginning indicated by the orientation of the zodiacal signs, and these circles are divided differently in each case. Possibly, the first sign ought to be identified as the ascendant, with each sign occupying an entire house thereafter, but this identification cannot be confirmed because the planetary positions are not equated with a time or date. Alternately, these ceilings may continue the tradition of the Mesopotamian pseudohoroscopes which did not consider the sign crossing the ascendant. At any rate, these depictions indicate dates of 141 and $148 \mathrm{CE}$, presumably the birthdays of the tombs' occupants.

\section{Medînet Habû}

Neugebauer presented five horoscopes from Medînet Habû:

Chicago MH 3377, dated to $13 \mathrm{CE}$; 
22 A Survey of Demotic Astrological Texts

An unnumbered Strasbourg ostracon, dated to $17 \mathrm{CE}$;

Thompson 1 + another unnumbered Strasbourg ostracon, dated to 18

CE;

Strasbourg D 270, dated to $35 \mathrm{CE}$; and

Thompson 2 which remains undated.

These horoscopes share not only a similar provenance, but also a similar composition. These ostraca adhere to a standard formula. First, they give the date for which the horoscope was cast, then the position of the sun and moon. Next, they list the Greek kentra (cardines): the ascendant, the descendant, the mid-heaven, and the lower mid-heaven. After these elements the ostraca inject some mystery: the ostraca present the $s w \check{s} p$ of the middle (or, possibly, of the opposition), the $s w s ̌ p$ of the left and the $s w \check{s} p$ of the right followed by two $t w r$, one on the right and one on the left. While the $t w r$ may have some relationship to the Mesopotamian DUR, ${ }^{82}$ the $s W \check{s} p$ do not appear in the Greek or Mesopotamian traditions. Finally, the horoscopes close with a list of the Greek topoi, or houses. Because the first house was included among the kentra, the ostraca begin with the second topos, called "Aıઠov Пú $\lambda \eta$ (Gate of Hades) in the Greek tradition, and continue in order.

When Neugebauer translated these horoscopes, he equated several of the houses with their counterparts among the topoi. Only one ostracon preserves the complete list of topoi, but in this case, the Demotic vocabulary varies - dni.t, ' and $p r$ seem to be used interchangeably. This linguistic variability is unexpected because in other instances dni.t translates the Greek word $\kappa \lambda \eta \hat{\rho} \rho \varsigma_{\text {, }}$ a term connected with the astrological doctrine of lots. Here, the first topos, $r^{c}-h^{c}$, had been counted among the kentra. This house corresponds to the Greek ஸ́робкómos. The Demotic phrase may be translated as 'place of rising,' roughly analogous to the occasional Greek name.

As noted above, the list of topoi began with the second house, called c

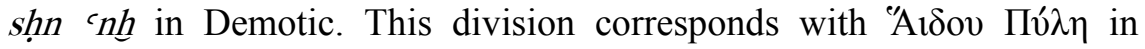
Greek and Inferna porta in Latin. Both of these names indicate some sort of entry into the underworld. Neugebauer translated this name as 'house of provisions of life,' but the analogy with the Latin name may be clarified if the Demotic name is considered as a reference to the depictions of funerary offerings often inscribed on tomb doors. However,

${ }^{82}$ Ross, 'DUR'.

Culture and Cosmos 
this house is also called ßíos, livelihood or manner of living, by Greek astrologers. ${ }^{83}$

The third house is called the dni.t sn, 'part [sic] of the brother,' which agrees with the interpretations, if not the same name, of the third house, called $\theta \varepsilon \alpha$ by the Greeks. Likewise, the fourth house is called dni.t it, 'part [sic] of the father.' This again agrees with the classical interpretation of the house, although Greek sources identify this topos as one of the kentra and call it 'Y $\pi$ ó $\gamma \varepsilon 10 v$. The fifth house is dni.t šry, 'part [sic] of the child,' obviously the counterpart for the Greek house

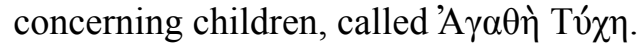

Neugebauer declines to translate the title of the sixth house: $t 3$ dni.t hne, others suggest Trennung, 'disconnection ${ }^{84}$ or abomination. ${ }^{85}$ In P. Berlin 8345 , this house is ascribed to wry, translated as the 'evil genius ${ }^{86}$ and 'monster. ${ }^{, 87}$ In both cases, the word is assumed to have derived from $w r$, 'great,' but perhaps the less common verb wrt 'to be tired' is appropriate: the final ' $t$ ' was probably indicated by an ' $\boldsymbol{\epsilon}$ ' in Coptic and both words share the 'bad bird' determinative ${ }^{88}$ According to the Greek

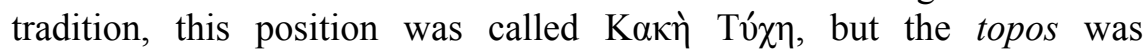
dedicated to sickness. Although Thompson declares šwne (sickness) to be 'hardly possible, ${ }^{89}$ the connection between this word and valetudo (health) is tempting. In fact, the Greek кókоৎ was occasionally translated into Coptic as $\boldsymbol{w} \boldsymbol{\omega} N \boldsymbol{\epsilon} .{ }^{90}$ Notwithstanding the allure of this identification,

\footnotetext{
${ }^{83}$ Paulus Alexandrinus, 24; Vettius Valens, IV, 12.

84 Wilhelm Spiegelberg, 'Die ägyptischen Namen um Zeichen der Tierkreisbilder', Zeitschrift für Ägyptische Sprache (1911), vol. 48, pp. 146-51.

${ }^{85}$ Hughes, Handbook, p. 62.

${ }^{86}$ This evidence was first drawn together by Herbert Thompson, 'Two Demotic Self-Dedications,' Journal of Egyptian Archaeology (Feb. 1941) [hereafter Thompson, 'Dedications', vol. 26, pp. 68-78, esp. p. 78.

${ }^{87}$ Thompson, 'Dedications', p. 78.

${ }^{88}$ W. Erichsen, Demotisches Glossar (Copenhagen, 1954), p. 96.

${ }^{89}$ Herbert Thompson, 'Demotic Horoscopes', Proceedings of the Society of Biblical Archaeology (1912), vol. 34, p. 230.

${ }^{90}$ Crum, Coptic, p. 570.
}

Culture and Cosmos 
QdM 'labourer" ${ }^{91}$ might also bear upon the interpretation. Because there was a conflation of $m$ and $n$ in Demotic and Coptic, such a writing would not be surprising. In fact, just such a conflation seems to be confirmed by the seventh house, dni.t shne, which Neugebauer translated as 'the part of the fate.' Indeed, the Greek word $\dot{\alpha} \pi \circ \tau \varepsilon \lambda \varepsilon \sigma \mu \alpha \tau \iota \kappa \alpha$ is sometimes rendered as shne, but according to the Greek tradition, the seventh house was the house of marriages. Here, shne should probably be read as marriage, because the Coptic verb cqume means 'to become a wife'. ${ }^{92}$

With the eighth house, 'shn $m t$ 'house of the provision of death', the Demotic scribe returns to calling the topoi by the Demotic word ', 'houses'. Again, this practice agrees with the Greek tradition which

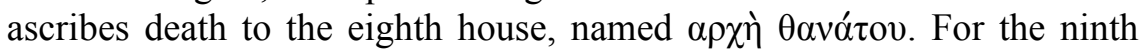
topos, the vocabulary changes, and dni.t ntr 'part of god' follows. This name agrees with the Greek tradition by which the ninth topos was called $\theta \varepsilon$ óc. For the tenth house, a slightly different term for house, $p r$, is used. Here, pr ntr.t, 'house of goddess' corresponds with the Greek name for the third house. Whereas the Greek system of topoi set the god and the goddess in opposition, the Egyptian system enumerated them sequentially. The Egyptian system may be reflected by Manilius, who associates Venus with the tenth place. ${ }^{93}$

The eleventh house, called $p^{3} \check{s} y$, is rendered as Psais by Neugebauer. The name may be translated as 'the Fate,' also the name of one of the lots. As Dorian Gieseler Greenbaum shows in her current research, a strong connection bound the agathos daimōn and agathe tuchē. Finally, the last house is called $p^{3} s \check{s} r$, the slaughtering demon. This term may also be found in the second tale of Setna Khaemuas. ${ }^{94}$ The connection with $\kappa \alpha \kappa o ̀ \varsigma \delta \alpha i ́ \mu \omega v$, the evil spirit, is clear, but these terms had a wider usage.

\section{Medînet Mâdi}

In 1983, Richard Parker presented 'A Horoscopic Text in Triplicate.' According to his hypothesis, the two ostraca, OMM 1060 and 1154, from Medînet Mâdi, a small town in the Fayyum, contain three instances of the same horoscope. This hypothesis may be rejected on the basis of better

\footnotetext{
${ }^{91}$ Crum, Coptic, p. 674a.

${ }^{92}$ Crum, Coptic, p. 385a.

${ }^{93}$ Astronomica 2.922. I thank Dorian Gieseler Greenbaum for this reference.

942 Setna Khaemuas 2.26.
} 
photographs which will appear shortly in the journal Egitto e Vicino Oriente.

\section{Unknown Provenance}

In 1968, Neugebauer and Parker added two more horoscopes. The first, Ashmolean D.O. 622, was assigned to the date of 38 BCE. The other, O. Berlin P. 6152, may be assigned to 57. Finally, George Hughes presented a horoscope from 59 .

\section{Conclusions}

Since 1943, changes, additions, and re-interpretations have been made to Neugebauer's original list of Demotic texts concerning the astral sciences. New connections to Mesopotamian have also been hypothesized and connections made with the Greek astrological corpus. Also, horoscopes have been identified in a wider variety of formats than previously thought. Undoubtedly, many texts have not yet been published. Unpublished astrological texts include P. Lille, many papyri of the Tebtunis library in Copenhagen, Florence and New Haven. Currently, the ostraca of Medînet Mâdi are in preparation for Egitto e Vicino Oriente.

With the addition of new material some questions are answered. For example, P. Vindob. D. 6286 agrees with the Mesopotamian precedent set by Enuma Anu Enlil. The topoi conform to the 'whole house' hypothesis proposed by Robert Hand ${ }^{95}$ However, other questions arise: did Egyptians ascribe an indigenous origin to the zodiacal signs? Did heliacal risings share the same schema presented by Susanne Denningmann? ${ }^{96}$ Did the rulerships of the triplicities first appear in Egypt? Did Ptolemy really find the terms listed in an old papyrus? What are the $t w r$ and $s w \breve{s} p$ mentioned in the horoscopes? Through a continued process of adding, revising, and interpreting, our knowledge of Demotic astrology will surely continue to grow.

\footnotetext{
${ }^{95}$ See Hand's article in this volume.

${ }^{96}$ See her article in this volume.
} 